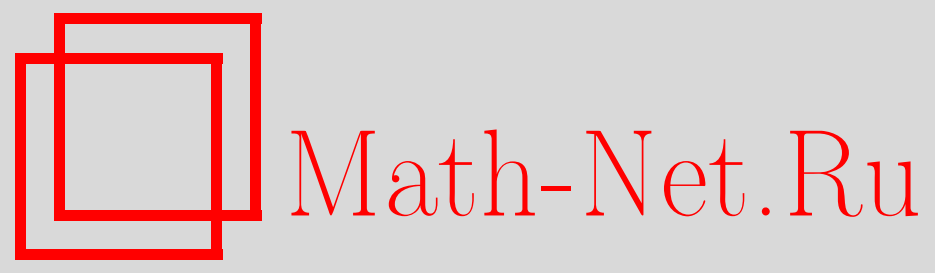

Н. Н. Андреев, А. М. Зубков, Г. И. Ивченко, В. Ф. Колчин, Ю. И. Максимов, Ю. И. Медведев, Б. А. Погорелов, Ю. В. Прохоров, В. Н. Сачков, Б. А. Севастьянов, Владимир Яковлевич Козлов (к девяностолетию со дня рождения), Дискрет. матем., 2004, том 16, выпуск 2, 3-6

DOI: https://doi.org/10.4213/dm663

Использование Общероссийского математического портала Math-Net.Ru подразумевает, что вы прочитали и согласны с пользовательским соглашением http://www.mathnet.ru/rus/agreement

Параметры загрузки:

IP : 3.85 .7 .115

26 апреля 2023 г., 13:24:41

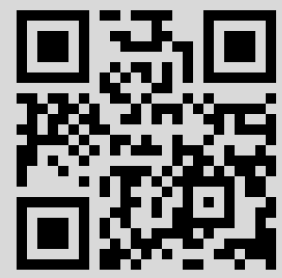




\section{Владимир Яковлевич Козлов \\ (к девяностолетию со дня рождения)}

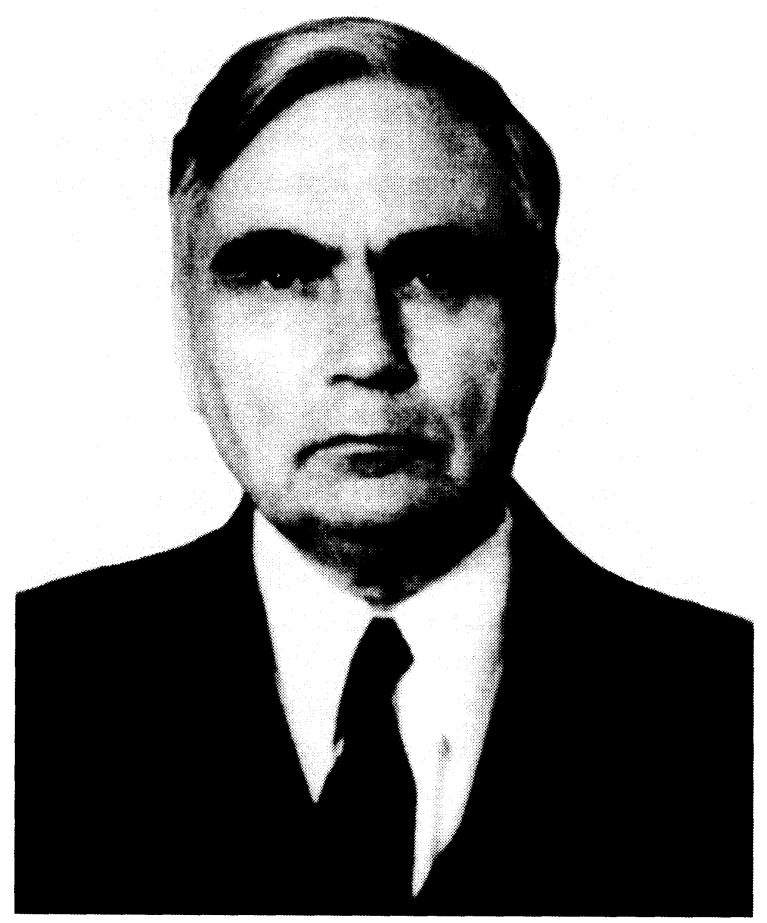

28 июня 2004 г. исполнилось 90 лет известному российскому математику, членукорреспонденту Российской Академии наук, действительному члену Академии криптографии Российской Федерации Владимиру Яковлевичу Козлову.

Владимир Яковлевич Козлов родился в Москве. После окончания школы в 1932 г. поступил на механико-математический факультет Московского государственного университета им. М. В. Ломоносова и после его окончания в 1937 г. - в аспирантуру.

По окончании аспирантуры В. Я. Козлов с 1940 по 1951 г. работал в Военной Академии бронетанковых и механизированных войск Советской Армии. После защиты докторской диссертации в 1951 г. В. Я. Козлов в 1952 г. стал профессором механико-математического факультета МГУ.

В это же время начинается более чем полувековая плодотворная творческая и научноорганизационная деятельность В. Я. Козлова в области криптографии и защиты информации. В 1966 г. Владимир Яковлевич Козлов избирается членом-корреспондентом Академии наук СССР.

В. Я. Козлов - воспитанник Лузинской школы математиков, ученик Нины Карловны Бари. Его статьи в «Докладах Академии наук» были представлены А. Н. Колмогоровым. В. Я. Козлов является ярким представителем отечественной школы теории функций и функщионального анализа. Ему принадлежат важные результаты по тригонометрическим рядам и рядам Фурье, ортогональным и биортогональным системам, базисам в различных функциональных пространствах. 
Первая публикация В. Я. Козлова [1] вышла в свет в год окончания МГУ в 1937 г. Согласно введенному Д. М. Меньшовым определению, нуль-рядом называется тригонометрический ряд

$$
\frac{a_{0}}{2}+\sum_{n=1}^{\infty}\left(a_{n} \cos 2 \pi n x+b_{n} \sin 2 \pi n x\right),
$$

сходящийся к нулю почти всюду на $[0,1]$, причем не все коэффициенты ряда равны нулю. В [1] В. Я. Козловым получены, в частности, следующие результаты: нуль-ряд может иметь только конечное число точек абсолютной сходимости; не существует нуль-ряда вида

$$
\sum_{n=1}^{\infty}\left(a_{n} \cos 2 \pi p^{n} x+b_{n} \sin 2 \pi p^{n} x\right),
$$

где $p$ - целое число.

В [3] доказано, что существует функция из $L_{2}[0,1]$, для которой ее ряд Фурье по полной ортонормированной системе функций на $[0,1]$ расходится на множестве мощности континуума. В [7] показано, что существует тригонометрический ряд, последовательность частных сумм которого расходится в каждой точке интервала $(0,1 / 2)$.

В [4] В. Я. Козлов вводит понятие $A$-совершенной системы функщий из $L_{2}[0,1]$ : система функций $\left\{\varphi_{\alpha}(x)\right\}$ называется $A$-совершенной, если вместе с каждой функцией $\varphi(x)$ системы ей принадлежат функции $\varphi(n x), n=2,3, \ldots$ Получен целый ряд критериев полноты $A$-совершенных систем, в том числе следующий достаточно просто формулируемый результат: $A$-совершенная система функций может быть полной только в том случае, если она порождена тремя функциями

$$
\begin{aligned}
& \varphi_{1}(x)=1, \\
& \varphi_{2}(x)=A_{1} \cos 2 \pi x+B_{1} \sin 2 \pi x, \\
& \varphi_{3}(x)=A_{2} \cos 2 \pi x+B_{2} \sin 2 \pi x,
\end{aligned}
$$

где постоянные $A_{1}, A_{2}, B_{1}, B_{2}$ удовлетворяют условию

$$
A_{1} A_{2}+B_{1} B_{2}=0 \text {. }
$$

В [3] В. Я. Козлов рассмотрел вопросы взаимосвязи между системой $\left\{\varphi_{n}(x)\right\}$ ортогональных нормированных функщий в $L_{2}[0,1]$ и системами их положительных и отрицательных частей. Пусть

$$
\varphi_{n}^{+}(x)=\max \left\{\varphi_{n}(x), 0\right\}, \quad \varphi_{n}^{-}(x)=\left\{-\varphi_{n}(x), 0\right\} .
$$

Тогда при условии полноты исходной системы оба ряда

$$
\sum_{n=1}^{\infty}\left(\varphi_{n}^{+}(x)\right)^{2}, \quad \sum_{n=1}^{\infty}\left(\varphi_{n}^{-}(x)\right)^{2}
$$

расходятся почти всюду.

В 1956 г. В. Я. Козлов выступил с докладом «Ортогональные и биортогональные системы функций» [11] на Третьем Всесоюзном математическом съезде. В докладе были подведены итоги развития теории таких систем, включая последние достижения по проблемам сходимости и расходимости рядов по ортогональным системам, по классификации базисов, исследованиям различных типов базисов, а также поставлен ряд новых задач. 
С 1951 г. под научным руководством В. Я. Козлова и при его активном участии были созданы теоретические основы разработки значительного числа отечественных шифрующих автоматов и генераторов криптографических ключей, обеспечивающих надежную защиту информации, передаваемой по различным каналам связи.

В. Я. Козлов отдает много сил научно-организационной деятельности. По его инищиативе в 1989 г. в стране появился новый академический журнал «Дискретная математика». В. Я. Козлов является главным редактором этого журнала со дня его основания. Под руководством В. Я. Козлова журнал привлекает для публикации статьи по различным направлениям дискретной математики и постоянно пополняется новым содержанием, включая, дополнительно к традищионным, такие направления как комбинаторные задачи теории чисел и алгебры, теорию кодирования, а также математические проблемы криптографии и защиты информации.

В. Я. Козлов сыграл значительную роль в организации и становлении Академии криптографии Российской Федерации. В 1991 г. несколько членов Российской академии наук поддержали инициативу создания такой академии. Это академики РАН Владимир Александрович Котельников, Юрий Васильевич Прохоров, члены-корреспонденты РАН Владимир Яковлевич Козлов, Владимир Константинович Левин (ныне академик РАН), Борис Александрович Севастьянов. Руководство Российской академии также поддержало эту инициативу, и 5 июня 1992 г. Указом Президента Российской Федерации Академия криптографии была создана.

Нельзя не отметить также роль В. Я. Козлова в организации в 1997 г. ежегодных выпусков «Трудов по дискретной математике», совместного издания РАН и Академии криптографии, являющегося приложением к журналу «Дискретная математика». Как главный редактор этого издания, В. Я. Козлов вносит важный вклад в повышение эффективности взаимной связи математики и криптографии.

В. Я. Козлов всегда окружен своими учениками, среди них число защитивших докторские и кандидатские диссертации находится на рубеже тридцати. Многие ученики В. Я. Козлова отмечают тот факт, что для глубокого понимания высказываемых им идей и их реализации всегда требовалось приложить серьезные усилия.

Научная и научно-организационная деятельность В. Я. Козлова высоко оценена государством. Владимир Яковлевич Козлов награжден орденом Ленина, орденом Октябрьской Революции, двумя орденами Трудового Красного Знамени, орденом Знак Почета, удостоен звания лауреата Государственной премии.

Коллеги и ученики от всей души поздравляют Владимира Яковлевича с юбилеем и желают ему здоровья, долгих лет жизни и дальнейших творческих успехов.

\section{Список литературы}

1. Козлов В. Я., О связи между абсолютной сходимостью и единственностью разложения функции в тригонометрический ряд. Докл. АН СССР (1937) 15, 417-420.

2. Козлов В. Я., О локальной характеристике полной ортогональной нормированной системы функций. Матем. сб. (1948) 65, 441-474.

3. Козлов В. Я., О распределении положительных и отрицательных значений ортогональных и нормированных функций, образующих полную систему. Матем. сб. (1948) 65, 475-480.

4. Козлов В. Я., О полноте системы функций $\{\varphi(n x)\}$ в пространстве $L_{2}[0,2 \pi]$. Докл. $A H C C C P$ (1948) 61, 977-980.

5. Козлов В. Я., О полноте системы функций $\{\varphi(n x)\}$ в пространстве нечетных функций из $L_{2}[0,2 \pi]$. Докл. AH СCCP (1948) 62, 13-16. 
6. Козлов В. Я., О базисах в пространстве $L_{2}[0,1]$. Матем. сб. (1950) 68, 85-102.

7. Козлов В. Я., О полных системах ортогональных функций. Матем. сб. (1950) 68, 351-364.

8. Козлов В. Я., К вопросу о полноте системы функций типа $\{\varphi(n x)\}$ в пространстве $L_{2}$. Докл. $A H$ CCCP (1950) 73, 441-444.

9. Козлов В. Я., Об одном обобщении понятия базиса. Докл. АН CCCP (1950) 73, 643-646.

10. Козлов В. Я., Пример Гольдовского. Матем. сб. (1951) 70, 197-204.

11. Козлов В. Я., Ортогональные и биортогональные системы функций. Труды Третьего Всесоюзного матем. съезда, т. 2. Москва, 1956, 27-28.

12. Козлов В. Я., О системах функиий типа $\{\varphi(n x)\}$ и мультипликативных системах изометрических операторов в пространстве $L_{2}[0,2 \pi]$. Диссертация на соискание ученой степени доктора физ.-матем. наук, 1950.

Н. Н. Андреев, А. М. Зубков,

Г. И. Ивченко, В. Ф. Колчин,

Ю. И. Максимов, Ю. И. Медведев,

Б. А. Погорелов, Ю. В. Прохоров,

В. Н. Сачков, Б. А. Севастьянов 